${ }^{1}$ Symkanych O.I., PhD, assoc. prof.; ${ }^{2}$ Maslyuk V.T., DrSci. (Physics), prof.;

${ }^{1}$ Boyko N.V., DrSci. (Biology), prof.; ${ }^{1}$ Tymoshchuk S.A., assistant; ${ }^{2}$ Svatiuk N.I., PhD;

${ }^{2}$ Pop O.M., PhD; ${ }^{1}$ Nyorba Bobikov M.M., lab.; ${ }^{2}$ Pitchenko G.F., leading engineer;

${ }^{2}$ Turkhovskij O.M., leading engineer; ${ }^{2}$ Romanyuk N.I., $\mathrm{PhD} ;{ }^{2}$ Megela I.G., leading

engineer; ${ }^{2}$ Tarnay O.A., engineer; ${ }^{2}$ Gajnish I.I., chief engineer

\title{
TIME EVOLUTION OF CHEMICAL, PHYSICAL PARAMETERS AND BIOLOGICAL ACTIVITY OF GLUCOSE AND SUCROSE AQUEOUS SOLUTIONS IRRADIATED ON A M-30 MICROTRON WITH AN ENERGY OF 12.5 MeV
}

\author{
${ }^{1}$ Uzhhorod National University, Pidhirna 46, 88000, Uzhhorod; \\ e-mail: olesjasi123@gmail.com \\ ${ }^{2}$ Institute of Electron Physics of the National Academy of Sciences of Ukraine, 21 \\ Universitetska Str., 88017, Uzhhorod
}

It is well known that studying the characteristics of water and aqueous solutions under the influence of external factors is very important due to their fundamental significance in the life of biota and for the environment [1]. This fact is also important for numerous applications where water serves as a working substance or mediator of the technological processes.

The questions on possible fractality and the lability of the structural units of water are a matter of permanent discussions even taken to account for the apparent simplicity of its chemical composition.

Radiation chemistry of water and aqueous solutions is another important area of research related to the realization of exotic chemical reactions, the formation of new chemical compounds, and the study of their biological activity $[2,3]$. The products of radiolysis of water have an indirect impact on the structure of DNA in living organisms, which is comparable to their destruction under the nuclear particles' irradiation. Taking into account that terrestrial radiation is a permanent factor in the existence of biota [4], the studies of kinetics and the peculiarities of the chemical and structural transformations of water and some aqueous solutions, as well as their effect on the metabolisms of living organisms, are also significant.
This paper presents the results of the complex studies of the radiolysis products of water and aqueous glucose/sucrose solutions.

The choice of glucose/sucrose, which are essential representatives of complex carbohydrates, is due to their widespread usage in medicine and the food industry.

The subject of study was the chemical, physical, and microbiological properties of distilled water, and its aqueous solutions, as well as their temporal evolution, after irradiation on the M-30 microtron of the IEF NAS of Ukraine.

\section{The objects and methods of studying}

The distilled water and aqueous glucose/sucrose solutions with a concentration of $5 \%$ were chosen as the selected objects for the studying. Glucose purity used for $99.8 \%$ solvents and $99.9 \%$ sucrose preparation. They all have a complex chemical structure, the elements of which have different sensitivity to the influence of radiation. Thus, glucose is a polyhydroxy aldehyde containing the carbonyl group and five hydroxy groups, sucrose is a more complex structure and consists of two monosaccharaides D-glucose and D-fructose.

Their molecular structures are characterized by the presence of hydroxy groups, various types of chemical bonding, and sensitivity to radiation. 
According to recent studies, the water features are specified by its complex polymer/fractal structure, lability, and the ability to form "water crystals/polymers" [5]. This possibility is caused by the presence of a specific type of hydrogen bonding, which is weak and easily broken. The structured state of water is a sensitive sensor of various external fields, and its clusters carry significant information [5].

The structural elements of water and glucose/sucrose with different sensitivity to the influence of external factors require unifying conditions of the radiation experiments, such as the maximum effect of radiation destruction of the selected solutions. Radiation studies were carried out by using the M-30 microtron of the Institute of Electronic Physics of the NAS of Ukraine, which parameters allow to smoothly regulate the energy of accelerated electrons within 1-25 MeV range with a mono-energy of $0.02 \%$ and a beam current of up to $50 \mu \mathrm{A}$. These allow forming intense fields of the electron, gamma, and neutron radiation in the field of fundamental and applied nuclear-physical research.

For the aims of the experiment, accelerated electrons' energy of $12.5 \mathrm{MeV}$ was selected, the irradiations were carried out at room temperature, the flux density was $5.5^{*} 10^{10}$ $\mathrm{el} . /\left(\mathrm{cm}^{2} \mathrm{sec}.\right)$, an integral flux of $2 * 10^{14} \mathrm{el} . / \mathrm{cm}^{2}$ was achieved for each irradiation cycle, which corresponds to a dose of $1 \mathrm{MRad}$. Irradiation's uniformity was not worse than $30 \%$ within an area of $100 \mathrm{~cm}^{2}$ and sufficient to locate three plastic cells, each hermetically sealed with a capacity of $50 \mathrm{ml}$. The scheme of the cyclic replacing of the samples was provided to ensure uniform conditions of irradiation of each sample. The selected electron flux density did not lead to heating of the samples; no gas phase evolution was observed during the irradiation process.

The beam of electrons with energies of 12.5 MeV provides radiation damage in solids similar to neutron or heavy-charged particles. This interaction leads to the creation of the irradiated materials not with local point defects, but significant areas of disordering.

Separate ionized/excited and isolated groups of molecules and structures are being created in all irradiated substances where permanent chemical interaction and element ordering is taking place.
The determination of the acidity of distilled water and the test solutions was performed by the potentiometric method using a $\mathrm{pH}$-meter AZ-8603. The $\mathrm{pH}$ values for the studied liquids were measured before and after their irradiation by high energy electrons. A glass electrode was used to measure the $\mathrm{pH}$ of the solutions.

The study of the electrophysical properties as the conductivity of aqueous solutions before and after irradiation provides information on the degree of their electrolytic dissociation.

The charge carriers of current in such solutions may be $\mathrm{H}^{+}, \mathrm{H}_{3} \mathrm{O}^{+}, \mathrm{OH}^{-}$, and charged fragments of damaged organic molecules. Measuring the DC conductivity of liquids is a complicated task that is why a comparative method on base of multimeter UNI-T UT-601 was used. By using this method, we can compare the measured resistance of a fluid with a reference by using amplifier feedback.

The volume of liquids between the electrodes plates was $1 \mathrm{~cm}^{3}$, and the voltage drop on them did not exceed $0.3 \mathrm{~V}$.

The optical transmission spectra were measured on the modified spectrometer SF-46 in the wavelength range of 200-1100 nm. A deuterium lamp was used as a source, which is designed to work in the spectral region from 190 to $350 \mathrm{~nm}$, an incandescent lamp - to work in the spectral range from 340 to $1100 \mathrm{~nm}$.

The investigated liquids were placed in 30 $\mathrm{ml}$ quartz cuvettes.

The biological effects of all the investigated solutions were measured by the detection of their antibacterial or stimulatory activities to the selected test microorganisms. Three strains of bacteria were used in study: Staphylococcus aureus, Escherichia coli, and Pseudomonas aeruginosa belonging to nonspore bacteria that differ in their phylogenetic origin and pathogenicity. Conditionally pathogenic microorganisms were represented by gram-positive and gram-negative clinical isolates (staphylococci and pseudomonads) and a gram-negative strain of commensal Escherichia coli lactose-positive strain. The $18 \mathrm{~h}$ cultures of all the microorganisms mentioned above had been used in the bacterial suspension form $\left(1.5 \times 10^{8} \mathrm{CFU} / \mathrm{ml}\right.$ of PBS) prepared according to $0.5 \mathrm{McF}$ arland density standards (measured by a densitometer Den-1). 
The purity of the culture was determined bacterioscopically by the gram staining and immersion microscopy techniques (Primo Star iLED, Carl Zeiss).

Selective chromogenic media, namely CHROMagar ${ }^{\mathrm{TM}}$ Staph aureus, CHROMID ${ }^{\circledR} \mathrm{P}$. aeruginosa Agar, and MacConkey E. coli Agar (Liofilchem) were used for the cultivation of chosen microorganisms before and after their exposure to irradiated solutions and in all the control groups. The number of microorganisms expressed in colony-forming units per $1 \mathrm{ml}$ $(\mathrm{CFU} / \mathrm{ml})$ was measured using ten-fold serial dilutions in Tecan ${ }^{\mathrm{TM}}$ Microplates, followed by their plating on the corresponding selective nutrient media mentioned above. The suspensions of test cultures of Staphylococcus aureus, Escherichia coli, and Pseudomonas aeruginosa, which were not treated by investigated solutions, had been taken as a positive control. The samples of the investigated irradiated solutions without any bacteria being added and served as a negative control. The irradiated water can restore its physics-chemical parameters in approximately 7-12 hours. Then the study of the effect of all solutions on the selected microorganisms was performed twice - immediately (ex tempore) after irradiation and after the restoration of its physical-chemical parameters - 24 hours after the irradiation; in both cases, the exposure time was two hours.

\section{The Results and Discussion}

There are eight samples were used in the experiments (glucose/sucrose solutions have a concentration of $5 \%$ ), Table 1 :

Table 1. Solutions and substances selected for investigation

\begin{tabular}{|l|l|l|l|}
\hline Sample & \multicolumn{1}{|c|}{ Name } & Sample & \multicolumn{1}{c|}{ Name } \\
\hline №1 & distilled irradiated water & №5 & dry sucrose in irradiated water \\
\hline №2 & distilled water unirradiated & №6 & dry glucose in irradiated water \\
\hline №3 & sucrose solution irradiated & №7 & dry irradiated sucrose in unirradiated water \\
\hline №4 & glucose solution irradiated & №8 & dry irradiated glucose in unirradiated water \\
\hline
\end{tabular}

The studies were carried out in two stages. In the first stage, the time dependences of the chemical and physical parameters of the irradiated water samples and glucose/sucrose solutions were investigated (Fig. 1,2) The technique of studying the time dependence of the characteristics of irradiated liquids was based on the following assumptions:

- Simple chemical formula and clean water structure lability are available, ability to restore its polymeric and physicochemical state. The time parameters of such relaxation and the chemical activity of fragments obtained after the radiation destruction of the solutions are unknown.

- The conditions of radiation treatment of liquids, (12.5 MeV electron energy and $1 \mathrm{MRad}$ irradiation dose) provide maximum fragmentation of glucose/sucrose molecules into elementary structural segments with $\left\{\mathrm{R}_{\mathrm{i}}\right\}$ sets. The final product of their assembling as the "Lego effect," depends on the structure of the $\left\{R_{i}\right\}$ sets and the characteristics of the aquatic environment, was it irradiated or not.
Fig. 1 shows the time dependences of $\mathrm{pH}$ values of the testing solutions indicated above (from 1 to 8 ). Our studies show the following trends:

- For water, the irradiation leads to a drop in $\mathrm{pH}$ value by $25-30 \%$, and it is gradually recovering with a time constant near about 900 $\mathrm{min}$. At the first moment stage, up to 50-70 min, there are the oscillations of its magnitude in the vicinity of $\sim 10 \%$ of the initial value are observed.

- The irradiation effects more significantly the $\mathrm{pH}$ value for glucose/sucrose solutions. Thus, for glucose, this change reaches $47 \%$ in the case of solution № 4 and 44\% for № 6 . For sucrose, the change in $\mathrm{pH}$ value is less small; for solution № 3 it is $31 \%$ and is $11 \%$ for № 5 . However, the difference between the $\mathrm{pH}$ values for irradiated glucose/sucrose solutions (samples № 4 and № 3) and the solutions of their irradiated materials in distilled water (samples № 6 / № 5), is more prominent. As can be seen Fig. 1, for glucose, the $\mathrm{pH}$ difference between samples 4 and 3 is only $3 \%$, for sucrose, samples 6 and 5, up to $6 \%$ of their initial value. As well 
$-95-$

as for irradiated water, there are oscillations of the $\mathrm{pH}$ value in the time dependences for glucose/sucrose solutions, samples № 4 and № 3, immediately after irradiation: for № 4 it consists near 3\%, for № 5 - almost $9 \%$. For solutions of these irradiated materials in unirradiated distilled water, the periodic structure of $\mathrm{pH}$ oscillations is absent, but their essential changes of its values take place within 20-40 min.

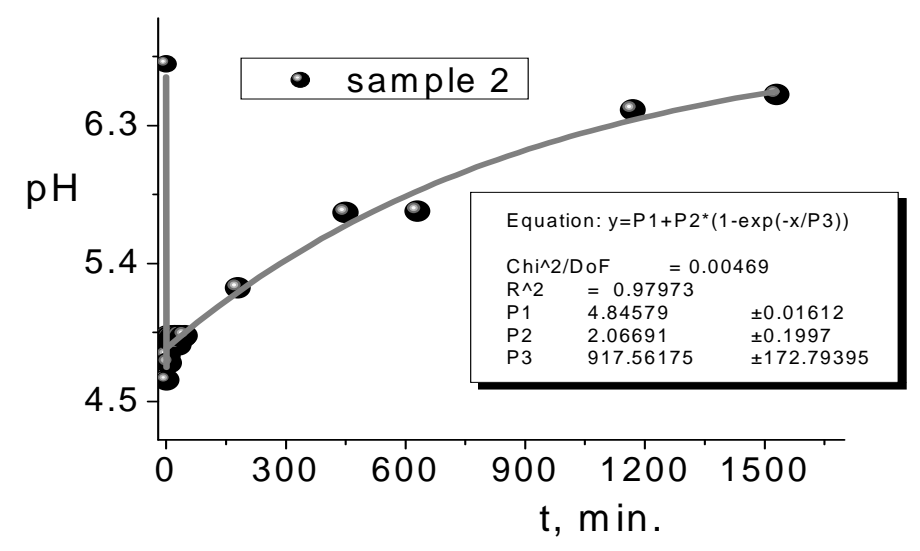

a)

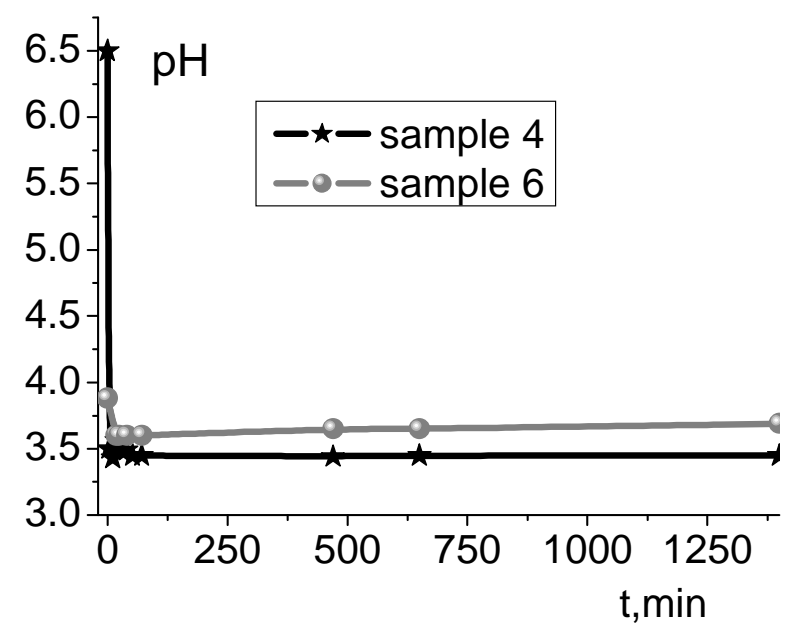

b)

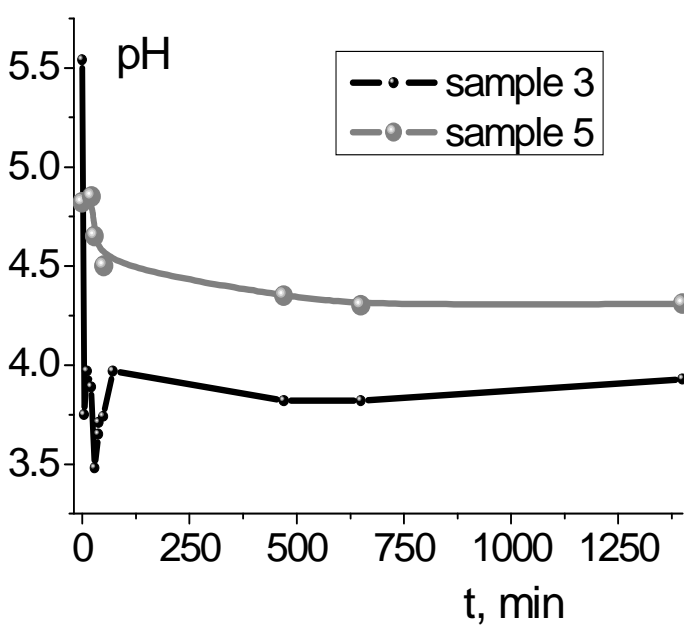

c)

Fig. 1. Time dependences of pH for liquids: a) irradiated water; b) glucose solutions (№ 4, 6) and c) sucrose solutions (№ 3, 5).

It should be noted that the $\mathrm{pH}$ indicators of sucrose solutions, samples 3 and 5, converge with time. For irradiated glucose solutions, the opposite temporal behavior was observed. During the observation period, the $\mathrm{pH}$ values for aqueous glucose/sucrose solutions did not recover to their original values, which before the start of irradiation were 6.5 and 5.5, respectively.
The optical transmission characteristics of irradiated and unirradiated liquids in the wavelength range of $200-1100 \mathrm{~nm}$ are presented in Fig. 2.

As can be seen, irradiation does not lead to the appearance of characteristic optical spectra with a fine structure, and there is no change at the edge of absorption. When for the 
-96-

distilled water (Fig. 2 a) irradiation leads to a photo-bleaching effect, then for the glucose/sucrose solutions (Fig. $2 \mathrm{~b}$ and c), the photo-darkening effect occurs. In the last cases, the optical transmission of the solutions decreases by $10 \%$ in almost the whole studied spectral range.

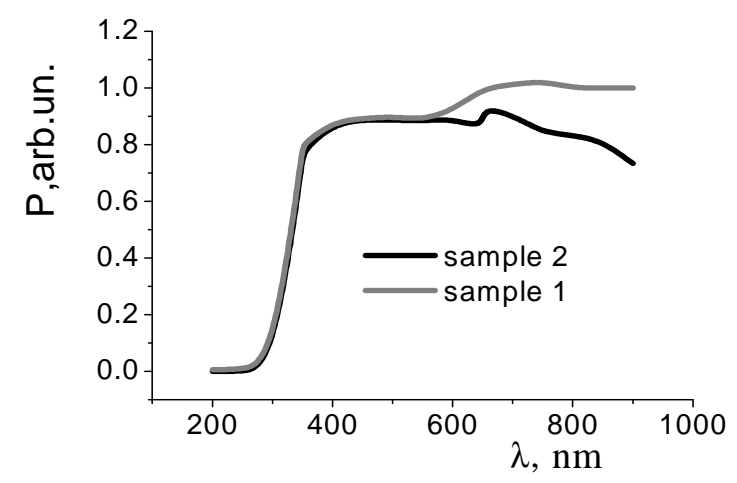

a)

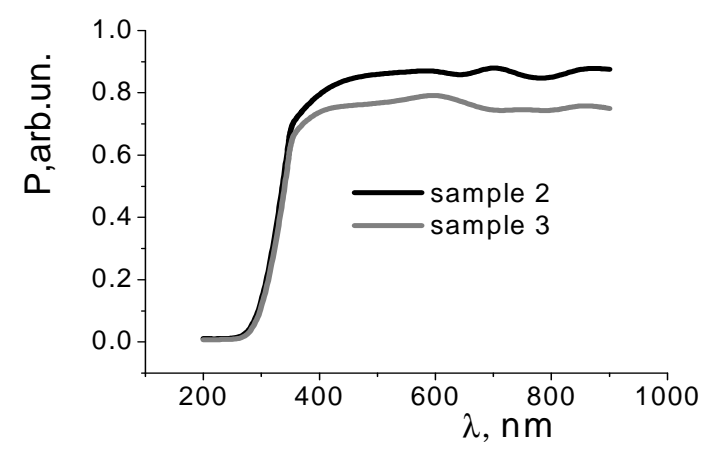

b)

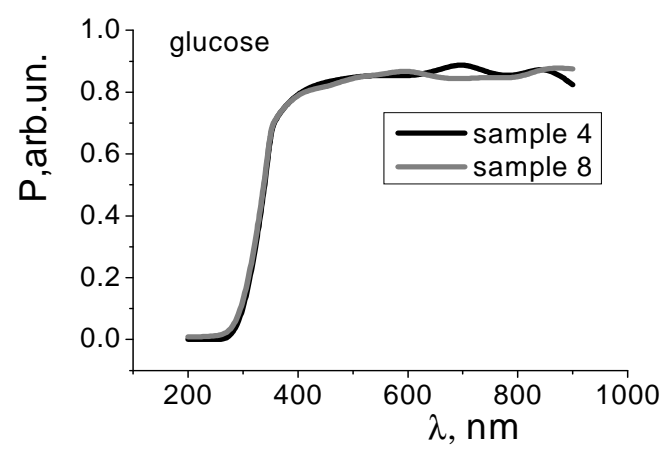

d)

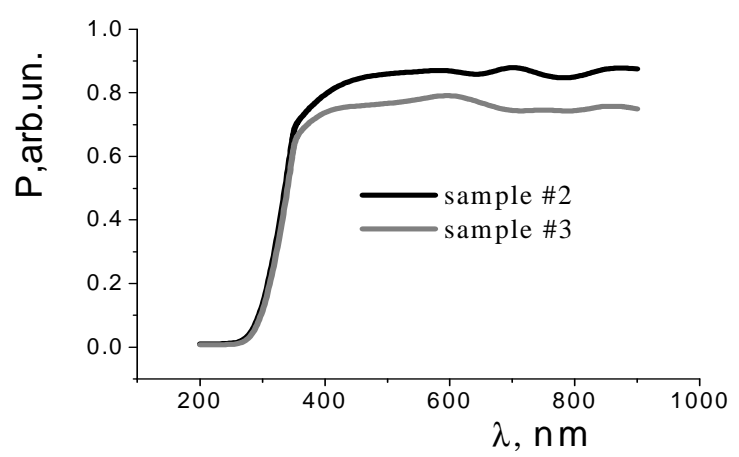

c)

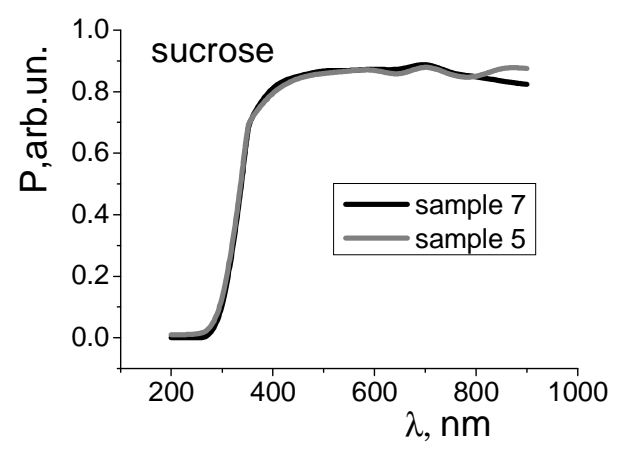

e)

Fig. 2. The dependences of the optical transmission of water samples (a) and solutions of glucose (b, d) and sucrose (c, e), dependencies 1 and 2 refer to unirradiated solutions of glucose / sucrose

As it is shown by our studies (Fig. $2 \mathrm{~d}$ and e), the optical properties are almost unchanged for the solutions containing irradiated glucose/sucrose ( 7,8 samples, Table 1) as well 
as when they are dissolved in irradiated distilled water $(5,6$ samples, Table 1$)$. The observed peculiarity in the transmission spectra of irradiated solutions and water in the 700-720 nm range may be caused by a hydrated electron [6].

Previous studies of the temporal changes of the electrophysical properties in the solutions No 1-8, see Table, indicate that their behavior has three specific time intervals. For the first of them, 5-10 minutes after irradiation, their resistance significantly, up to $50 \%$, decreases compared to the initial value of all studied solutions. In the second one, up to $60-100$ minutes, the irradiated sucrose solution, sample No. 3, had higher resistance or lower conductivity on $20 \%$ compared to the same parameters of distilled water. Sample No 4, glucose solution, on the contrary, was smaller by the same value. The third time interval is realized after the day or two, where the conductivity values of the irradiated glucose/sucrose solutions become almost compared.

The interpretation of the obtained results is possible on current ideas about the destruction of water and aqueous solutions under the radiation. It is based on a 3-stage process [6]. The first one is physical and realized under the direct radiation action and is accompanied by destruction/ionization of molecules or the excitation of their structural fragments. The next one is physico-chemical when the effect of radiation becomes in equilibrium with the reverse reactions of reconstruction of the molecular segments in the water environment and the process deionization molecules themselves.

The last stage, named as chemical one, which occurs after irradiation and is the final reassembling or reconstruction of the irradiated molecular product through its structural segments as "Lego effect". Atomic hydrogen $(\mathrm{H})$, hydroxyl $(\mathrm{OH})$, and hydrogen peroxide $\left(\mathrm{H}_{2} \mathrm{O}_{2}\right)$ have the highest chemical activity among free radicals formed after irradiation of liquids. The products of radiolysis have extremely high chemical activity and can oxidize almost all organic substances that make up the living organisms. Nucleic acids have the highest sensitivity to radiation's effects, both in direct interaction reactions and through radiolysis products of the aqueous medium.
Time dependences of biomedical parameters of irradiated water samples and glucose/sucrose solutions had been investigated as a second step of the experiments. The studied samples of irradiated distilled water demonstrated an inhibitory effect on the clinically isolated strain of Staphylococcus aureus immediately after irradiation while causing complete inhibition of these microorganisms' growth, creating a bacteriostatic effect only (see table 2, figure 3 ).

This effect was depressed for 24 hours, and the growth of Staphylococcus aureus restored to the number of microorganisms accounted for $2.5 \times 10^{4} \mathrm{CFU} / \mathrm{ml}$. This effect was similar to the values typical of non-irradiated water $\left(2.0-2.5 \times 10^{4} \mathrm{CFU} / \mathrm{ml}\right)$.

It is interesting that when dissolving preirradiated dry sugars in non-irradiated water or, conversely, dissolving non-irradiated dry sugars in irradiated water, no significant differences in their antibacterial effects (complete inhibition of staphylococci growth immediately after irradiation and the number of microorganisms (from $1 \times 10^{4}, 1.6 \times 10^{4}, 1.4 \times 10^{4}$ to $2.4 \times 10^{4}$ $\mathrm{CFU} / \mathrm{ml}$ ) had been observed. The only exception was a solution of non-irradiated (native) sucrose dissolved in irradiated water, which had resulted in less significant (incomplete) inhibition of staphylococci immediately after exposure to irradiation at the control level - distilled nonirradiated water $\left(2 \times 10^{3} \mathrm{CFU} / \mathrm{ml}\right)$.

The trends of the tested solutions effects were significantly different when studying their effects on the strain of Escherichia coli, the well-known gram-negative commensal microorganism. None of the solutions were able to demonstrate complete inhibition of this bacterium immediately after irradiation. Exposure to irradiated distilled water causes the highest inhibitory effect. At the same time, diminish the growth of the tested E. coli strain to $1 \times 10^{2} \mathrm{CFU} / \mathrm{ml}$ and $6 \times 10^{3} \mathrm{CFU} / \mathrm{ml}$ ex tempore and 24 hours after irradiation, respectively (see table 2, figure 1). An irradiated glucose solution and a solution made from dry irradiated glucose were dissolved in non-irradiated water led to similar effects. However, opposite tendencies had been noted for sucrose solutions, which, in case of dry irradiation and subsequent dissolution in non-irradiated water, and especially when dissolved in the native form in irradiated water, demonstrated distinct 
antibacterial properties. Without significantly affecting the given microorganisms growth on the first day, they were able to inhibit its growth until complete elimination 24 hours after the irradiation. Only the irradiated sucrose solution exhibits some particularities in action while causing specific inhibition of E. coli's growth immediately after irradiation $-3 \times 10^{3} \mathrm{CFU} / \mathrm{ml}$ and having no significant effect after 24 hours $\left(1 \times 10^{7} \mathrm{CFU} / \mathrm{ml}\right)$. In this experiment, like qualitative testing preceding quantification, we did not observe any significant effect in distilled non-irradiated water.

The most important from a practical point of view was obtained for the treatment with all the investigated solutions of clinically isolated strains of Pseudomonas aeruginosa (see table 4, figure 3). The most significant influences were released by irradiated sucrose and glucose solutions. The exposure to which of the tested pathogenic strain of pseudomonads resulted in the complete elimination of these microorganisms, both ex tempore and 24 hours after irradiation. The sufficiently strong inhibitory effect was observed when using dry irradiated glucose dissolved in non-irradiated water (complete growth absence immediately after irradiation and $5 \times 10^{1} \mathrm{CFU} / \mathrm{ml} 24$ hours after it). However, a similarly prepared sucrose solution did not have such effect and led to less significant inhibition of this microorganism's in vitro growth $\left(1 \times 10^{5}\right.$ and $\left.2 \times 10^{5} \mathrm{CFU} / \mathrm{ml}\right)$.

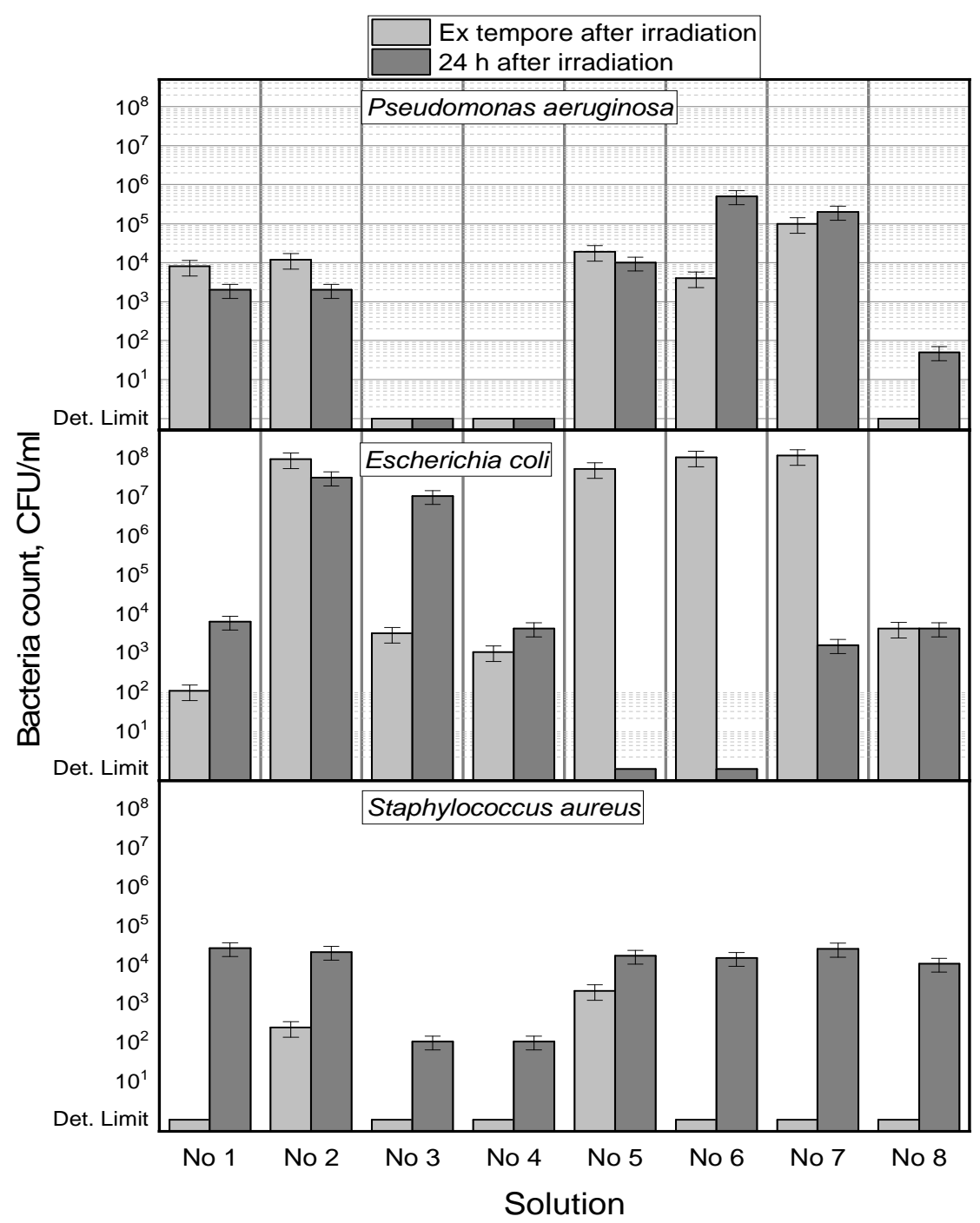

Fig. 3. The effect of irradiated solutions No. 1-8 on the grows of the selected strains of microorganisms. 
-99-

Table 2. The effect of irradiated solutions on Staphylococcus aureus

\begin{tabular}{|c|c|c|c|c|c|}
\hline \multirow[t]{2}{*}{ No } & \multirow[t]{2}{*}{ Type of investigated solution } & \multicolumn{2}{|c|}{$\begin{array}{l}\text { Bacterial count, } \\
\text { CFU / ml }\end{array}$} & \multicolumn{2}{|c|}{$\begin{array}{l}\text { Control of bacterial culture } \\
\text { growth and sterility of } \\
\text { investigated solution }\end{array}$} \\
\hline & & Stage 1 & Stage 2 & Stage 1 & Stage 2 \\
\hline 1 & Distilled water - irradiated & NG & $2.5 \times 10^{4}$ & CG & NG \\
\hline 2 & Distilled water unirradiated & $2.3 \times 10^{2}$ & $2.0 \times 10^{4}$ & CG & NG \\
\hline 3 & The sucrose solution is irradiated & $\mathrm{NG}$ & $1 \times 10^{2}$ & CG & NG \\
\hline 4 & The glucose solution is irradiated & NG & $1 \times 10^{2}$ & CG & NG \\
\hline 5 & Sucrose in irradiated water & $2 \times 10^{3}$ & $1.6 \times 10^{4}$ & CG & NG \\
\hline 6 & Glucose in irradiated water & NG & $1.4 \times 10^{4}$ & CG & NG \\
\hline 7 & $\begin{array}{lcc}\begin{array}{l}\text { Dry } \\
\text { unirradiated water }\end{array} & \text { sucrose } & \text { in } \\
\text { liated } & & \end{array}$ & NG & $2.4 \times 10^{4}$ & $\mathrm{CG}$ & NG \\
\hline 8 & $\begin{array}{lcc}\text { Dry irradiated } & \text { glucose } & \text { in } \\
\text { unirradiated water }\end{array}$ & NG & $1 \times 10^{4}$ & CG & NG \\
\hline
\end{tabular}

$\mathrm{CG}$ - continuous [strong] growth; NG - no growth

Table 3. The effect of irradiated solutions on Escherichia coli

\begin{tabular}{|c|c|c|c|c|c|}
\hline \multirow[t]{2}{*}{$\begin{array}{l}\mathrm{N} \\
\mathrm{o}\end{array}$} & \multirow[t]{2}{*}{ Type of investigated solution } & \multicolumn{2}{|c|}{$\begin{array}{l}\text { Bacterial count, } \\
\mathrm{CFU} / \mathrm{ml}\end{array}$} & \multicolumn{2}{|c|}{$\begin{array}{l}\text { Control of bacterial culture } \\
\text { growth and sterility of } \\
\text { investigated solution }\end{array}$} \\
\hline & & Stage 1 & Stage 2 & Stage 1 & Stage 2 \\
\hline 1 & Distilled water - irradiated & $10^{2}$ & $6 \times 10^{3}$ & CG & NG \\
\hline 2 & Distilled water unirradiated & $9 \times 10^{7}$ & $3 \times 10^{7}$ & CG & NG \\
\hline 3 & The sucrose solution is irradiated & $3 \times 10^{3}$ & $1 \times 10^{7}$ & $\mathrm{CG}$ & NG \\
\hline 4 & The glucose solution is irradiated & $1 \times 10^{3}$ & $4 \times 10^{3}$ & $\mathrm{CG}$ & NG \\
\hline 5 & Sucrose in irradiated water & $5 \times 10^{7}$ & NG & CG & NG \\
\hline 6 & Glucose in irradiated water & $1 \times 10^{8}$ & NG & $\mathrm{CG}$ & NG \\
\hline 7 & $\begin{array}{lrlr}\begin{array}{l}\text { Dry } \\
\text { unirradiated water }\end{array} & \text { sucrose } & \text { in } \\
\end{array}$ & $1.1 \times 10^{8}$ & $1.5 \times 10^{3}$ & $\mathrm{CG}$ & $\mathrm{NG}$ \\
\hline 8 & $\begin{array}{lrrr}\begin{array}{l}\text { Dry irradiated } \\
\text { unirradiated water }\end{array} & \text { glucose } & \text { in } \\
\end{array}$ & $4 \times 10^{3}$ & $4 \times 10^{3}$ & CG & NG \\
\hline
\end{tabular}

$\mathrm{CG}$ - continuous [strong] growth; $\mathrm{NG}$ - no growth

Table 4. The effect of irradiated solutions on Pseudomonas aeruginosa

\begin{tabular}{|c|c|c|c|c|c|}
\hline \multirow[t]{2}{*}{$\begin{array}{l}\mathrm{N} \\
\mathrm{o}\end{array}$} & \multirow[t]{2}{*}{ Type of investigated solution } & \multicolumn{2}{|c|}{$\begin{array}{l}\text { Bacterial count, } \\
\quad \mathrm{CFU} / \mathrm{ml}\end{array}$} & \multicolumn{2}{|c|}{$\begin{array}{l}\text { Control of bacterial culture } \\
\text { growth and sterility of } \\
\text { investigated solution }\end{array}$} \\
\hline & & Stage 1 & Stage 2 & Positive & Negative \\
\hline 1 & Distilled water - irradiated & $8 \times 10^{3}$ & $2 \times 10^{3}$ & CG & NG \\
\hline 2 & Distilled water unirradiated & $1.2 \times 10^{4}$ & $2 \times 10^{3}$ & CG & NG \\
\hline 3 & The sucrose solution is irradiated & NG & NG & $\mathrm{CG}$ & NG \\
\hline 4 & The glucose solution is irradiated & NG & NG & CG & NG \\
\hline 5 & Sucrose in irradiated water & $1.9 \times 10^{4}$ & $10^{4}$ & $\mathrm{CG}$ & NG \\
\hline 6 & Glucose in irradiated water & $4 \times 10^{3}$ & $5 \times 10^{5}$ & $\mathrm{CG}$ & NG \\
\hline 7 & $\begin{array}{lrrr}\begin{array}{l}\text { Dry irradiated } \\
\text { unirradiated water }\end{array} & \text { sucrose } & \text { in } \\
\end{array}$ & $1 \times 10^{5}$ & $2 \times 10^{5}$ & $\mathrm{CG}$ & NG \\
\hline 8 & $\begin{array}{lrl}\begin{array}{l}\text { Dry irradiated } \\
\text { unirradiated water }\end{array} & \text { glucose in } \\
\end{array}$ & $\mathrm{HP}$ & $5 \times 10^{1}$ & $\mathrm{CG}$ & NG \\
\hline
\end{tabular}

$\mathrm{CG}$ - continuous [strong] growth; $\mathrm{NG}$ - no growth 


\section{Conclusions}

The obtained results are showing the peculiarities of the time evolution of chemical, physical and biological properties, especially of water and glucose/sucrose solutions irradiated by 12.5 MeV fast electrons with a dose of $1 \mathrm{MRad}$. The long-term effects in the range of 7-10 hours of partially restoring their properties, especially water, can demonstrate their cluster and polymeric structures. On the other hand, the irreversibility results of some parameters of these aqueous solutions after irradiation can be caused by their structural destruction. The $\mathrm{pH}$ values of water and aqueous glucose and sucrose solutions were changed by more than $50 \%$ after irradiation with a dose of $1 \mathrm{Mrad}$. The chemical compound destruction up to its elementary complexes and the processes of its partial reduction makes it possible to create the new chemical compounds as the "Lego effect."

High biological activity observed on the irradiated solutions indicates their selective action on microorganisms from different phylogenetic groups. The antibacterial effects of irradiated water and glucose/sucrose solutions have differed significantly in the specificity of activities and strength of manifestation. As can be seen, it not only depends on the sort of microorganism but also on time after the irradiation (cooling time) when the irradiated solutions were used.
The understanding of the mechanisms of such influences and their practical applications requires further research.

\section{References}

1. UNESCO World Water Assessment Programme. The United Nations world water development report 2020: water and climate change. Paris: United Nations Educational, Scientific and Cultural Organization, 2020. P. 219.

2. Pikaev A.K., Ershov B.G. Primary products of the radiolysis of water and their reactivity. Russ Chem Rev. 1967, 36(8), 602-620. Doi: 10.1070/RC1967v036n08ABEH001675.3. Hiroshi Yamaguchi, Yukio Uchihori, Nakahiro Yasuda, Masashi Takada, Hisashi Kitamura. Estimation of Yields of $\mathrm{OH}$ Radicals in Water Irradiated by Ionizing Radiation. J. Radiat. Res. 2005, 46(3), 333341.4. Svatyuk N.I., Maslyuk V.T., Symkanych O.I. Radiological monitoring, concepts: "radiation weather" and "radiation identification of long". Scientific Bulletin of Uzhhorod University. Series. Physics. 2018, 44, 99-108.

5. Saber Naserifar, William A. Goddard Liquid water is a dynamic polydisperse branched polymer. Proceedings of the National Academy of Sciences Feb. 2019, 116(6), 1998-2003. Doi: 10.1073/pnas.1817383116.

6. Adams G.E., Boag J.W., Michael B.D. Aqueous Solutions Containing Oxygen Transient Species Produced in Irradiated Water. Proc. R. Soc. Lond. 1966, 289, 321-341. Doi: 10.1098/rspa.1966.0014.

Стаття надійшла до редакції: 08.02.2020.

\title{
TIME EVOLUTION OF CHEMICAL, PHYSICAL PARAMETERS AND BIOLOGICAL ACTIVITY OF GLUCOSE AND SUCROSE AQUEOUS SOLUTIONS IRRADIATED ON A M-30 MICROTRON WITH AN ENERGY OF 12.5 MeV
}

\author{
${ }^{1}$ Symkanych O.I., ${ }^{2}$ Maslyuk V.T., ${ }^{1}$ Boyko N.V., ${ }^{1}$ Tymoshchuk S.A., ${ }^{2}$ Svatiuk N.I., ${ }^{2}$ Pop \\ O.M., ${ }^{1}$ Nyorba Bobikov M.M., ${ }^{2}$ Pitchenko G.F., ${ }^{2}$ Turkhovskij O.M., ${ }^{2}$ Romanyuk N.I., \\ ${ }^{2}$ Megela I.G., ${ }^{2}$ Tarnay O.A., ${ }^{2}$ Gajnish I.I.
}

${ }^{1}$ Uzhhorod National University, Pidhirna 46, 88000, Uzhhorod; e-mail: olesjasi123@gmail.com

${ }^{2}$ Institute of Electron Physics of the National Academy of Sciences of Ukraine, 21 Universitetska Str., 88017, Uzhhorod

The results of complex chemical, physical parameters and biological effects of the time evolution of water and glucose/sucrose solutions characteristics irradiated on an M-30 micron (12.5 MeV, $1 \mathrm{MRad}$ ) are presented. The eight samples of liquids (solutions) with different 
compositions had been choosing for investigations. Water radiolysis products have a significant indirect effect on the structure of DNA in living organisms, which is comparable to their destruction under direct radiation impact.Given that terrestrial radiation is a permanent factor in the existence of biota, the study of kinetics and the peculiarities of chemical-structural transformations for irradiated water, aqueous solutions, and their effects on the living organisms is also important. Glucose/sucrose, which are important representatives of complex carbohydrates had been chosen in this study due to their widespread use in medicine and the food industry.This paper establishes the temporal regularities, both long- and short-term, on the transformation of chemical, physical properties, and biological activity of the mentioned above solutions. On the example of microorganisms from different phylogenetic origin (Staphylococcus aureus, Escherichia coli, Pseudomonas aeruginosa), the biological action of irradiated solutions was determined, depending on the irradiation dose and the method of solution preparation: irradiated glucose/sucrose solutions and distilled water; irradiated dry glucose/sucrose in irradiated water; irradiated dry glucose/sucrose in irradiated water. It was found that the all irradiated samples exhibit a greater inhibitory effect on the strain of Pseudomonas aeruginosa compare to the other tested bacterial strains. It has been also shown that irradiated sucrose and glucose solutions introduced into suspensions of this pathogenic strain resulted in it complete elimination immediately after irradiation and $24 \mathrm{~h}$ after irradiation. Solution of dry irradiated glucose in irradiated water shows complete absence of growth immediately after irradiation and $5 \times 10^{1} \mathrm{CFU} /$ $\mathrm{ml} 24$ hours after irradiation, however, a similar sucrose solution does not show this effect. Less profound but still strong efficacy had been observed to tested strain of staphylococci, but not to E. coli commensal bacterial strain.

Experiments of this kind were conducted for the first time, so they are of scientific and practical importance, both in the applied sciences and in medicine.

Keywords: water; irradiated water; aqueous glucose/sucrose solutions; radiation; M-30 micron; pH; optics; strains; biological action; selectivity.

\section{References}

1. UNESCO World Water Assessment Programme. The United Nations world water development report 2020: water and climate change. Paris: United Nations Educational, Scientific and Cultural Organization, 2020. P. 219.

2. Pikaev A.K., Ershov B.G. Primary products of the radiolysis of water and their reactivity. Russ Chem Rev. 1967, 36(8), 602-620. Doi: 10.1070/RC1967v036n08ABEH001675.Hiroshi Yamaguchi, Yukio Uchihori, Nakahiro Yasuda, Masashi Takada, Hisashi Kitamura. Estimation of Yields of OH Radicals in Water Irradiated by Ionizing Radiation. J. Radiat. Res. 2005, 46(3), 333-341.4. Svatyuk N.I., Maslyuk V.T., Symkanych O.I. Radiological monitoring, concepts: "radiation weather" and "radiation identification of long". Scientific Bulletin of Uzhhorod University. Series. Physics. 2018, 44, 99-108.

5. Saber Naserifar, William A. Goddard Liquid water is a dynamic polydisperse branched polymer. Proceedings of the National Academy of Sciences Feb. 2019, 116(6), 1998-2003. Doi: 10.1073/pnas.1817383116.

6. Adams G.E., Boag J.W., Michael B.D. Aqueous Solutions Containing Oxygen Transient Species Produced in Irradiated Water. Proc. R. Soc. Lond. 1966, 289, 321-341. Doi: 10.1098/rspa.1966.0014 